\title{
Narración e identidad
}

\author{
Narration and Identity
}

Jaime Alberto Galgani

Universidad Católica Raúl Silva Henríquez. Santiago, Chile.

jgalganim@ucsh.cl

\section{RESUMEN}

Considerando la crisis de los relatos tratada desde distintos planteamientos teóricos, el presente artículo discute las posibilidades de los discursos narrativos para definir y dar forma al concepto de "identidad"; específicamente, “identidad latinoamericana”. El autor presenta seis dificultades para acercarse al tema y concluye con una propuesta orientada a enfrentar los discursos identitarios.

Palabras claves: Identidad, lenguaje, escritura, oralidad, cultura de masas, discurso.

\begin{abstract}
Considering the crisis of the stories put forward from diverse theoretical approaches, this article addresses the possibilities of narrative discourses to define and outline the concept of identity, particularly Latin-American identity. The writer presents six difficulties to approach the topic and arrives at a proposal oriented towards facing identifying discourses.
\end{abstract}

Keywords: Identity, language, writing, oral language, culture of masses, discourse.

Recibido: 25-03-2009. Aceptado: 20-05-2009.

*El presente artículo es el resultado de una ponencia presentada con el mismo título en el Corredor de las Ideas, Capítulo de Paraguay, Universidad Católica de Asunción, Asunción, en julio de 2008 . 
in duda, la crisis de la Modernidad arrastró consigo un cúmulo de crisis $\checkmark$ secundarias. Una de ellas tiene que ver con las posibilidades ciertas que tenemos para narrar desde la escritura el contenido de nuestra(s) indentidad(es). Por cierto, el optimismo positivista del siglo XIX y de la primera parte del siglo XX dio lugar a un relativismo hoy en día fuera de discusión, a pesar de los intentos neomodernistas por reflotar el discurso de la realidad latinoamericana. Por lo menos, nos queda la sospecha como una herida, como una arruga en el planchado difícil de obviar, como una glosa a la que siempre habrá que recurrir cada vez que hablemos de lo "nuestro" para evitar suspicacias de ingenuidad o totalitarismo, como un "sin embargo" que ya no nos es posible omitir si queremos estar al día con los diversos pliegues del discurso contemporáneo, con sus críticas, con su quehacer metadiscursivo, con su puesta en discusión de la objetividad moderna y con su presunción de que "lo real" no es accesible a la palabra.

En efecto, según Roger Chartier, “'Temps d'incertitude', 'epistemological crisis', 'tournant critique', tales son los diagnósticos, en general sombríos, postulados en estos años respecto a la disciplina histórica" (Chartier, 2006: 7). Siendo la Historia la principal afectada por la evolución epistemológica operada, sin duda, es también el tópico de la identidad el que queda medularmente atravesado por dicho cuestionamiento, cuestión que no es menor, pues podría subsumir el discurso relacionado con la materia en una inmovilización esterilizante que no sería útil para nadie, excepto para el servicio de las ideologías globalizadoras que buena pesca pueden obtener de este "río revuelto". Por este motivo, el interés de esta ponencia consiste en revaluar las posibilidades de un discurso identitario y alentar la sensibilidad en función de recuperar esas voces no suficientemente valoradas y que buena contribución pueden hacer a la hora de definir qué somos, qué queremos ser y cuál es el contenido de nuestros sueños e idearios.

En primer lugar, deseo formular y describir -sin duda superficialmente- seis dificultades que he alcanzado a elencar, con el deseo de recibir aportes ulteriores que puedan ampliar o discutir la validez de este listado. A saber:

La primera dificultad está dada por la distancia entre el narratario y lo narrado, entendiendo como narratarios a todos los agentes discursivos que, desde la llegada de Cristóbal Colón, se han propuesto la tarea de definir en qué consiste la identidad latinoamericana (lo narrado). Dicho acometimiento se emprendió sin ningún escrúpulo desde el primer día del descubrimiento, puesto que una ingente seguidilla de cronistas, relatores, intelectuales y escritores, se entretuvo aparentemente sin obstáculos en la descripción de la naturaleza, los animales y los pueblos descubiertos y conquistados tras la empresa colonizadora. La 
sospecha sobre dichos relatos es reciente y comenzó en el momento en que se logró establecer que el ejercicio escritural siempre viene dado como una visión que viene desde "el otro". Ciertamente es así, en la época colonial, cuando el distanciamiento entre el mundo europeo y el mundo "americano" es abismante y resulta incomprensible entender cómo desde una óptica cultural resueltamente diversa es posible acercarse certeramente a un universo de significación eminentemente enigmático. La distancia se hace más radical cuando, más allá de la cuestión lingüística, cultural y religiosa, se imponen las actitudes elusivas del mundo aborigen, el cual -después de su primera ingenuidad con respecto a los conquistadores- comprende que debe desarrollar estrategias evasivas para lograr sobrevivir en una realidad que se le ha hecho definitivamente hostil. Esta evasividad, sinuosidad y repliegue del mundo indígena quita valor a la "visión de los vencedores", pues -con la imposición de la cruz y la espada- los conquistadores y colonizadores lograron dominar los territorios y posesiones del nuevo mundo, pero no alcanzar su corazón ni el núcleo de sus misterios, permaneciendo este "otro" en un lugar inaccesible al discurso. Por otro lado, las narrativas posteriores - provenientes de escritores mestizos- aunque pueden acercarnos mejor a la cuestión identitaria, no superan el hecho de estar ya sometidas al influjo del adoctrinamiento cultural que supone la asimilación de una lengua que no es la propia. De este modo, la llamada "visión de los vencidos" estaría, en su origen, inoculada por el virus de lo europeo que, ingresado por medio de la lengua, incorpora sus categorías epistemológicas propias. Mayor sospecha merecen los trabajos de los pensadores del siglo XIX, los cuales derechamente piensan América desde Europa, y ya no desde la Europa española, sino desde la que acaban de descubrir ellos mismos en sus viajes, sus contactos familiares y sus lecturas, es decir, la Europa ilustrada. Evidentemente, la lectura de América de Alberdi, Sarmiento, Bello, e incluso de algunos más recientes, como Alcides Arguedas y Octavio Paz, es una visión externa del fenómeno americano, por cuanto comporta, además, una intencionalidad proyectual explícita en la línea de edificar las naciones republicanas con un patrón culturalista explícitamente eurocentrista.

La segunda dificultad que advierto tiene que ver con la naturaleza de la escritura como fenómeno advenidizo a las tierras americanas. En efecto, la escritura llega a nuestro continente constituyéndose hegemónicamente en el único artefacto descriptivo, bajo el título de un poder indiscutible, una especie de superchería cultural que hace de ella un fetiche ante la cual toda otra discusión resulta irrelevante (Lienhard, 1992). Por otro lado, la empresa escrituraria colonizadora consiste en reducir un mundo "no escrito" a la escritura, tarea que -vista desde nuestros tiempos- resulta evidentemente reductiva. ¿Es posible 
dar este salto sin violencia, sin pérdida? La pregunta viene de más al fondo: ¿Es posible reducir toda realidad al lenguaje? En este sentido hemos sido recipientes y herederos de una tradición cultural europea que asignó a la escritura el valor de un espejo, como si fuera posible vaciar "el mundo en un libro". Los europeos que llegaron continuaron con esta práctica ya secular para ellos y nosotros la adoptamos no sin ingenuidad, olvidando los repliegues inasibles de la realidad, su complejidad y sus grietas. Desde Borges en adelante, caímos en la cuenta de que tal pretensión era ilusa y que todo relato no puede sino dar cuenta de una ficción. Así, por ejemplo, tenemos los relatos de Juan Carlos Onetti, quien - con su saga de Santa María- una y otra vez nos invita a cuestionar la figura del escritor frente a sus objetos narrativos, poniendo en evidencia la distancia que los separa. El escritor está aquí y el mundo de "allá" no se resuelve en el tránsito a lo escrito sino como un proceso de filtración y de transformación que fuerza todos los sentidos que la realidad pudiera tener.

Un tercer nivel de dificultad está dado por el hecho de que toda escritura comporta, en su raíz, una matriz ideológica gracias a la cual pervive y gracias a la cual puede emitir un veredicto. Escribir es enjuiciar. La alternativa sería el silencio del místico, la revelación del vidente, una experiencia similar a la contemplación del "Aleph" borgeano, que no nos es posible narrar a menos que poseyéramos la lengua de los dioses, pero, como dice Barthes en su famosa lección inaugural, al no poseer tal lengua privilegidada nos contentamos con esa "engañifla" que llamamos literatura (Barthes, 1982).

Ahora bien, aceptado el supuesto de que en el momento mismo de escribir estamos aceptando una matriz ideológica determinada, toda escritura no puede ser sino "fascista", monológica y totalitaria, por cuanto supone cribar unos criterios y rechazar otros. Ante esta evidencia, la pluralidad de lo real permanece como una incógnita y la dinámica excluyente de la narración identitaria permanece como una voz amputada ex ante de la ambicionada objetividad del observador. Esta limitación se hace más radical aún cuando se trata del trabajo intelectual individual, práctica que nos hace recordar a muchos culturalistas latinoamericanos que, encerrados en su biblioteca, en medio de sus libros y en el silencio sobrecogedor de su "cuarto propio", se dedicaron a pensar, leer y describir el mundo americano. También nos hace pensar en los ilustrados escritores citadinos que, para informarse de la realidad que querían abordar, visitaban, libreta y lápiz en mano, los reductos constitutivos de su preocupación (el campo, las minas, los cités, las cárceles, los manicomios, los prostíbulos, las poblaciones indígenas, los mercados, etc.). De esta literatura, que dio en llamarse realista, costumbrista o naturalista, vivió el mundo americano gran parte del siglo XIX y las primeras décadas del siglo XX y, lo peor de todo, a ella asignó el título y el 
valor de una narrativa que bien hablaba de nuestra identidad, desconociendo que no era más que una visión siempre externa y superficial de la misma.

En cuarto lugar, más radical aun nos resulta comprender este aspecto desde que asumimos, con Lacan, la distinción entre lo Real, lo Imaginario y lo Simbólico, momento en que comenzamos a sospechar de la capacidad significativa del "significante". Con Lacan descubrimos que nos movemos en medio del lenguaje, que el sujeto es obra del lenguaje, que nuestro discurso no es más que un encadenamiento metonímico de significantes en cuya red no se nos revela el sentido sino a través de un ejercicio de omisión del mismo, es decir, intentando captar aquello que de "lo real" puede encaminarse hacia nosotros por la vía de lo que el discurso omite, censura u oprime. Descubrimos también que lo simbólico sólo nos conduce a un "saber" sobre el Sujeto y no al "ser" del mismo. Desde esta perspectiva, ¿no será que los relatos identitarios auténticos, ajenos al lenguaje, sólo pueden ser alcanzados a través de otras expresiones? ¿ $\mathrm{O}$, simplemente, que nos está vedado saber lo que somos? ¿O que hay que aceptar que, en medio de la escritura, la identidad se nos revela apenas por las brechas o cuñas del "ser" que, por vía pulsional, se introducen en las grietas del lenguaje? ¿Y, quién puede acceder a dicha sabiduría: el gramático, el historiador, el psicosociólogo o el profeta?

En quinto lugar, suponiendo que todos estos cuestionamientos no tengan validez y que sí podemos confiarnos en el poder descriptivo de la escritura, nos queda por delimitar cuáles son los contenidos propios de lo que llamamos identidad. Durante un tiempo, se pensó que escribir sobre América era poner el acento en sus hombres, sus costumbres, sus tradiciones folclóricas, sus vestimentas, sus giros lingüísticos particulares. Fue así que la literatura abundó en huasos, ponchos, boleadores, compadritos y gauchos. Y así surgió la distinción entre "color local" y "universalismo". Los criollistas criticaban a los escritores que abundaban en temas europeos. Borges, en su ensayo "El escritor argentino y la tradición" (1932) salió al encuentro de esta discusión para plantear con una serie de ejemplos que tal dilema era falso. En efecto, planteó que nadie piensa que Racine deja de ser francés por haber escrito tragedias ambientadas en la época antigua, con tópicos clásicos y personajes griegos. Y nadie consideró que Shakespeare fuera menos inglés por haber ambientado sus mejores dramas en Italia, Irlanda o Escocia. Asimismo, alude al Corán, argumentando que nadie duda de su condición "árabe" a pesar de no aparecer en ellos la mención de al menos un camello. Como contraparte, deconstruye uno de los relatos más preclaros de la "argentinidad" como es Don Segundo Sombra, postulando que una de las tradiciones que más concurren en su elaboración es la del simbolismo francés. Así también, plantea que lo que hace que un relato sea revelador de una 
identidad determinada no es la presencia de tópicos regionales o "nacionales" (como mucho gustaban los criollistas), sino la vigencia de un tono particular que revela la situación desde la cual se habla, la focalización del relator, el ángulo del hablante. De este modo, Borges juzga que sus relatos serán siempre argentinos, aunque en ellos hable de laberintos, minotauros e infinitos.

En este sentido, he pensado que en la literatura chilena, un relato considerado "típicamente nuestro", como es Sub terra (1904) de Baldomero Lillo, en el cual se narra la azarosa y desventurada vida de los mineros del carbón de Lota, a fines del siglo XIX e inicios del XX, recoge las influencias del naturalismo de Emile Zola en Germinal y las lecturas de Bret Harte, relatos que escuchó Baldomero Lillo siendo niño cuando su padre -quien había participado de las búsquedas mineras en la fiebre del oro en California- leía a sus hijos al calor del hogar familiar, en las lluviosas tardes del sur. Ahora bien, siguiendo las observaciones de Borges, dicho relato no por acoger tales influencias deja de ser "chileno".

Más ejemplos. El cancionero popular chileno (así como el resto de América Latina) cuenta con dos tradiciones: una que contiene una mirada de los asuntos folclóricos desde la ciudad (Los Quincheros, Los Huasos de Algarrobal) que abunda en huasos, chamantos, cántaros de greda, rodeos, etc., y de giros considerados campesinos ("mecón”, "agüaita”, "güendar"). Esta industria folclórica ha considerado que esos son los tópicos constitutivos del nacionalísimo concepto de "chilenidad" y con ellos han deleitado y cansado a generaciones completas. Cualquier extranjero que los siga, entendería que el típico chileno anda siempre con poncho y ojotas, y que los pueblos tienen muchos cántaros de greda y tejados coloniales; gran sorpresa reciben los turistas cuando ven que lo que sí hay en todas partes son sucursales del BancoEstado y Mac Donald's distribuidos por doquier.

Al contrario, la verdadera poesía y el canto popular, el que nace en los campos o en los barrios, adolece casi por completo de esos abusos criollistas. Sus temas son universales (el amor, el odio, el luto, la muerte, la religiosidad) y su lengua es la de todos los hispanohablantes. Hasta en sus estructuras métricas la poesía popular es universalista, pues usa privilegiadamente el romance, la redondilla y la décima. ¿En dónde está, entonces, la raigambre identitaria? Pues bien, lo está en la tonalidad, en el giro dramático o lúdico que no se observa en los contenidos sino en el tratamiento que a ellos se les da, en la visión de la vida y de la muerte, en el providencialismo vigente, en la presencia secular de los ángeles y los demonios, en los fantasmas tutelares, en la parentela que se asoma completa en los relatos. Distinguir qué es lo identitario en dichos relatos exige una labor más precisa y un ojo más atento, pues la identidad no se revela 
como un bloque definido y perentorio que se establezca como "diferencia" con respecto a las demás narrativas o líricas populares de la región, sino como una marea que conjunta las esperanzas, dolores, razones y sinrazones de toda la humanidad, de tal manera que "lo chileno" pueda reconocerse como propio en medio de temáticas que son comunes a otros pueblos. Un primer ejemplo, quiero ofrecer al recordar un concurso estudiantil de "monólogos clásicos" al que tuve la oportunidad de asistir en la ciudad de Talca durante el año 2007. Uno de dichos monólogos consistía en un fragmento del Lazarillo de Tormes, recitado por un estudiante campesino. El texto es el mismo que conocemos, ninguna variación en las palabras o temas. Sin embargo, viéndolo (y sólo oyéndolo) resultaba evidente de que quien lo hacía era un joven campesino chileno, cuya identidad se revelaba en la recitación de un texto ciertamente universal. Era la apostura de su voz, las inflexiones en la recitación, la intencionalidad de su elocución, la picardía propia (distinta de la española) lo que daba color al recitado. Un segundo ejemplo, quiero poner en una de las canciones de nuestra conocida folclorista Violeta Parra, uno de los fragmentos de "Volver a los 17". A saber:

El amor es torbellino

de pureza original.

Hasta el feroz animal

susurra su dulce trino,

detiene a los peregrinos,

libera a los prisioneros,

el amor con sus esmeros

al viejo lo vuelve niño

y al malo sólo el cariño

lo vuelve puro y sincero (1985 [1964-1965]).

¿Qué palabra típicamente chilena se advierte en esta estrofa? Ninguna. ¿Algún tópico criollista recurrido? Ninguno. Sin embargo, la secular apropiación de la décima con sus versos octosílabos da cuenta de un rasgo característico de nuestra identidad folclórica cultural. La décima es para el cantor popular chileno tan propia como es el sexteto para el seguidor argentino de Martín Fierro. Por otra parte, no hay tampoco novedad en el tema, que -como se puede advertir- es simplemente universal: el amor con su fuerza arrebatadora y transformadora que es capaz de hacer cantar a los animales, liberar a los prisioneros, rejuvenecer a los viejos, convertir a los malos y proporcionar solaz a los peregrinos. Tema que conecta este canto popular con las más diversas poéticas 
antiguas y modernas, de aquí y acullá; cristiano y judío, oriental y occidental, antiguo y viejo, nada menos novedoso que el amor. Sin embargo, cantado en la voz de Violeta Parra, con su voz particular y con su guitarreo de fondo, nos hace irremediablemente escuchar la voz de las cantoras del campo y de nuestras abuelas en las tertulias familiares. La misma canción, cantada por Violeta Parra es chilena y cantada por Mercedes Sosa, se hace argentina. Lo que comunica acento e identidad no es la escritura sino la voz. Lo que hace propio un canto no es la abundancia de los temas locales sino la apropiación de los que son universales.

En esta misma línea, un tercer ejemplo que quiero ofrecer tiene que ver con el canto "a lo humano y a lo divino", género tan particularmente querido por los cantantes populares.

El muy noble emperador

Carlomagno y sus vasallos

cayeron como unos rayos

destruyendo al gran señor.

Allí reinaba el error

la estupidez, la ignorancia;

triste fue la circunstancia

al verse en aquella tierra,

sufriendo una cruda guerra

LOS DOCE PARES DE FRANCIA... (anónimo, citado por Astorga, 2000).

Se aplican a este fragmento las mismas consideraciones planteadas más arriba, con la salvedad de que aquí nos encontramos con un tema que ya no es ni siquiera universal, sino simplemente francés. ¿Qué hace un tópico francés en la lírica popular chilena o latinoamericana? Pues, simplemente nos encontramos de nuevo con la validación que proporciona el concepto de apropiación.

Un último ejemplo nos ofrece la variante que incluye algunas inflexiones lingüisticas propias:

El que nace pa' cantor

y quiere ser afamao

necesita buen cuidao,

estudiar más y mejor.

Encomendarse al Señor

y saber muy bien vivir, 
nunca tratar de afligir

a otro humilde cristiano;

con el guitarrón en mano

cantando me hei de morir (anónimo, citado por Astorga , 2000).

Queda por agregar que la lírica popular, la de los guitarrones y fogatas, a menudo, pertenece a la tradición oral, sujeta a variaciones de pueblo en pueblo formando un corpus de relatos que, en su gran parte, jamás llegan a transformarse en escritura y que, en las más afamadas competencias, luce la destreza de la improvisación.

Por último, cabe destacar la arremetida abismante y por cierto inmensurable de la ingente cantidad de productos textuales que surgen día a día a través de los nuevos recursos tecnológicos, gracias a los cuales toda voz que quiera puede ser pronunciada. Blogs, foros, chats y otras variedades parecen indicar que ya no bastan las voces oficiales y que el emergimiento de la cultura de masas -iniciado hace más de un siglo con la aparición de diarios, revistas y cine y continuado con la radiodifusión y la televisión- termina hallando un acabamiento sugerente con esta eclosión de la red. Sin embargo, no sólo se trata de una continuidad en el proceso, sino un verdadero cambio de paradigma, pues, como nunca antes, se hace posible escuchar voces dispares, fragmentarias, yuxtapuestas, contradictorias muchas veces, desjerarquizadas y desvinculadas de los poderes comunicacionales, los cuales -a su vez- están vinculados a diversos poderes o contrapoderes. Esta nueva cultura no hace sino problematizar más la cuestión de la identidad, al tiempo que parece atomizar los discursos, sometiéndolos al arbitrio de un azar en el que todo es posible. La proliferación de textos es tal que la tentación natural es sucumbir ante ellos y es difícil establecer una línea de conexión entre todos ellos, a menos que sea aquella que da cuenta de la casi absoluta libertad y la conexión de los discursos locales con los universales. De hecho, la Red ha permitido desvincularnos del secular imaginario que nos concibe como un pueblo aislado, al mismo tiempo que nos facilita generar una serie de conexiones totalmente paralelas e independientes; el rizoma informático, al mismo tiempo que nos acerca a nuestros intereses, nos permite "pasar" de todo lo que está lejos de nuestro ánimo cultural, afectivo, político, social, etc. Como nunca, también, el ser humano se ve menos sometido a discursos hegemónicos y la fuerza de los mismos parece no tener otro marco que el de la llamada "globalización" ordenada según los parámetros ordenadores del neoliberalismo.

La Red ha facilitado, como contraparte, que las nuevas referencias no estén tan centradas en el concepto de "nación" o de "ciudad", sino el de comunidad. 
Sin embargo, los nexos de dichas instancias de encuentro parecen ser más débiles que cualquier otro nexo previo. Las comunidades nacen y desaparecen tan rápido como las adscripciones particulares a ellas. La apoteosis de la libertad individual consagra ese derecho de sumarse y de quitarse en el momento menos pensado. Y, así como los apegos vuelan, también lo hacen las palabras que quedan divagando en los meandros infinitos de la Red, desaliñadas y sueltas, inconexas y variadas, casi como los rumores bullangueros de una feria, donde sólo de vez en cuando alcanza a distinguirse una voz de la otra.

Hecho este rápido balance, no queda más que concluir que hoy nos resulta extremadamente difícil hablar de identidad y que se ha desmoronado la fuerza de los textos que parecían habérnosla definido. Parece ser que la crisis de los relatos llega a instalar una pregunta abiertamente desnudadora y crítica sobre el sentido de nuestro ser. Estamos solos en el mundo, temerosos de quienes nos rodean e ignorantes de nosotros mismos. Ya no tenemos a los dioses y tampoco parecemos estar cerca de alguna revelación próxima que nos saque de la "intrascendencia”. Los más desprovistos, con tal de no estar solos, intentan acogerse a cualquier ideología totalizante aunque ella contenta la sospecha de que, al absolutizar lo relativo, estamos relativizando lo absoluto, llegándose a darse el caso, por ejemplo, de que importe más una pobre identidad arrancada del color de la piel o de la pandilla a la que se pertenece que la conciencia occidental largamente trabajada con respecto al valor de la vida humana.

\section{CONCLUSIONES Y PROPUESTA}

Queda sin embargo, la pregunta sobre cómo trabajar o acercarse a una noción de identidad, dado el diagnóstico presentado. Mi intuición quiere proponer algunos puntos a tener en cuenta:

En primer lugar, es de Perogrullo decir que ya no podemos aproximarnos al discurso de la identidad con la noción de verdad occidental por delante. Menos aún, intentar soslayar el hecho de que el contenido de la verdad debe actuar más como resultado de un proceso que como un axioma o antecedente ideológico que somete a todos con el baremo de la adhesión o del rechazo.

Es necesario, también, quitar a la escritura su estatuto de poder, su jerarquía de fetiche, su indolente seguridad y su desparpajo para dictaminar verdades y falsedades. La idolatría del discurso escrito desconoce el valor de la oralidad y a los agentes que la transmiten de generación en generación. La palabra escrita, centrada en la sobrevaloración del contenido ilustrado olvida las voces marginadas que no han tenido acceso a la escritura sino a través de aquellos que han 
escrito en su nombre: campesinos, indígenas, obreros, amas de casa, pandillas populares, lenguas locales, etc.

En tercer lugar, hay que comprender que la identidad, al estar vinculada al ámbito del ser, no puede ser alcanzada por la palabra, la cual sólo nos comunica con un saber que siempre es contenedor de un filtro ideológico.

En cuarto lugar, hay que comprender que el dinamismo narrativo sobre cualquier tema latinoamericano (o universal) no puede ser ya, desde el fin de la época moderna en la literatura y el pensamiento, más que un relato multivocal. Los nuevos discursos se arman, desde hace varias décadas, a varias voces, que son el resultado -a su vez- de varias miradas. Ante este panorama, los grandes intelectuales, las voces únicas y mayores ya no tienen las mismas posibilidades de existir que hace un siglo.

En quinto lugar, la identidad no es un valor que se pueda poseer, sino una dimensión a la cual sólo podemos acercarnos... y acercarnos recordando que lo que podemos alcanzar de ella no es más que, a veces, una pálida intuición.

Es necesario percibir que toda narrativa identitaria es siempre elusiva; cuando se cree tenerla "asida", en ese momento se nos escapa. Por eso mismo, a la identidad se la debe mirar de reojo, pues ella no quiere ser sorprendida. Así como el movimiento de los electrones para Heisenberg, el discurso sobre la identidad no es un objeto indiferente a su observador, pues ella está inscrita necesariamente en el marco de la subjetividad.

Para configurar un discurso más integral sobre la identidad es necesario asumir una mirada holística, recuperar el decir de lo popular, de la danza, del canto, de lo religioso, de la música, etc., es una tarea urgente en este sentido.

No son los "temas" lo que define la identidad de un pueblo o comunidad, sino las tonalidades que se resuelven en la viva manifestación de su ser. El punto no está en mirar lo que se escribe, sino desde dónde se lo hace... y cómo ese "dónde" configura acentos e inflexiones particulares.

Finalmente, y también de Perogrullo, recordar siempre que no existe identidad "pura", ya que somos el resultado de mixturas, hibridaciones, transposiciones; incluso los pueblos precolombinos lo eran. Quizás esta última consideración nos libre de nacionalismos y localismos absurdos que de vez en cuando afloran en nuestros países.

\section{REFERENCIAS}

Astorga Arredondo, Francisco.2000. "Elcantoalopoeta", en RevistaMusicalChilena 54. (En línea). Disponible en: http://www.scielo.cl/scielo.php?script=sci_ 
arttext\&pid=S0716-27902000019400007\&lng=es\&nrm=iso. Consulta: 09/11/2009.

Barthes, Roland. 1982. El placer del texto: seguido por "lección inaugural de la cátedra de Semiología lingüística del Collège de France”. Trad. por N. Rosa y O. Terán. México: Siglo XXI.

Borges, Jorge Luis. 1932. "El escritor argentino y la tradición” en Discusión, Buenos Aires: Editorial Manuel Gleizer.

Chartier, Roger. 2006. La historia entre relato y conocimiento. Santiago: Ediciones UCSH, Cuadernos de Ideas 9.

Lienhard, Martín. 1992. La voz y su huella: escritura y conflicto étnico-cultural en América Latina 1492-1988. $3^{a}$ edición aumentada. Perú: Editorial Horizonte.

Lillo, Baldomero. 1904. Sub terra. Cuadros mineros. Santiago: Imprenta Moderna.

Parra, Violeta. 1995. Volver a los 17. Selección de Juan Andrés Piña. Santiago: Los Andes. 